\title{
Feasibility of Cu-Al-Mn superelastic alloy bar as a self-sensor material
}

\section{$\operatorname{AUTHOR}(\mathrm{S})$ :}

Shrestha, K. C.; Araki, Y.; Yamakawa, M.; Yoshida, N.; Omori, T.; Sutou, Y.; Kainuma, R.

\section{CITATION:}

Shrestha, K. C....[et al]. Feasibility of Cu-Al-Mn superelastic alloy bar as a self-sensor material. Journal of Intelligent Material Systems and Structures 2015, 26(3): 364-370

\section{ISSUE DATE: \\ 2015-01-14}

URL:

http://hdl.handle.net/2433/193667

\section{RIGHT:}

(C) The Author(s) 2014. Reprints and permissions: sagepub.co.uk/journalsPermissions.nav. DOI: 10.1177/1045389X14529028. jim.sagepub.com; This is not the published version.

Please cite only the published version.; この論文は出版社版でありません。引用の際には 出版社版をご確認ご利用ください。 
Manuscript submitted for possible publication in Journal of Intelligent Material Systems and Structures Feasibility of Cu-Al-Mn superelastic alloy bar as a self-sensor material by Shrestha et al.

1 Technical Note

2

3 Feasibility of $\mathrm{Cu}-\mathrm{Al}-\mathrm{Mn}$ superelastic alloy bar as a self-sensor material

4

5 Kshitij C Shrestha ${ }^{1}$, Yoshikazu Araki ${ }^{1}$, Makoto Yamakawa ${ }^{2}$, Nobutoshi Yoshida ${ }^{1}$,

6 Toshihiro Omori ${ }^{3}$, Yuji Sutou ${ }^{3}$ and Ryosuke Kainuma ${ }^{3}$

7

$8 \quad{ }^{1}$ Department of Architecture and Architectural Engineering, Kyoto University, Kyoto, Japan

$9 \quad$ 2Department of Architecture, Tokyo Denki University, Tokyo, Japan

$10 \quad{ }^{3}$ Department of Materials Science and Engineering, Tohoku University, Sendai, Japan

11

12 Corresponding author:

13 Yoshikazu Araki, Department of Architecture and Architectural Engineering, Kyoto University, Kyoto

14 615-8540, Japan.

15 Email: araki@archi.kyoto-u.ac.jp 
Manuscript submitted for possible publication in Journal of Intelligent Material Systems and Structures Feasibility of Cu-Al-Mn superelastic alloy bar as a self-sensor material by Shrestha et al.

\section{Abstract}

18 This paper examines the feasibility of $\mathrm{Cu}-\mathrm{Al}-\mathrm{Mn}$ superelastic alloy (SEA) bars as possible self-sensor

19 components, taking electrical resistance measurement as a feedback. SEA bars change their

20 crystallographic structure with phase transformation, as well as electrical resistance during

21 loading-unloading process at ambient temperature. This work studies the relationship between strain and

22 electrical resistance measurements of SEAs at room temperature. Such relationship can be used in

23 determining the state of a SMA-based structure effectively, without separate sensors, by appropriately

24 measuring the changes in electrical resistance during and after structure's loading history. Quasi-static

25 cyclic tensile tests are conducted in this paper to investigate the relationship between electrical

26 resistance and strain for a $4 \mathrm{~mm}$ diameter $\mathrm{Cu}-\mathrm{Al}-\mathrm{Mn}$ SEA bar. It was demonstrated that linear

27 relationship with little hysteresis can be achieved up to $10 \%$ strain. The test observations support the

28 feasibility of newly developed Cu-Al-Mn SEA bars, characterize by low material cost and high

29 machinability, as a multi-functional material both for structural and sensing elements.

\section{$31 \quad$ Keywords}

32 Cu-Al-Mn, superelastic alloy (SEA), shape memory alloy (SMA), self-sensor, electrical resistance

33 feedback 
Manuscript submitted for possible publication in Journal of Intelligent Material Systems and Structures Feasibility of Cu-Al-Mn superelastic alloy bar as a self-sensor material by Shrestha et al.

\section{Introduction}

36 The interest has been increasing on the use of innovative materials as multi-functional

37 components, that would act both as structural components as well as self-sensing components (Housner et al., 1997). Structural control and seismic applications of shape memory alloys (SMAs) to civil engineering structures have been studied by a number of researchers (Dolce et al., 2000; Ozbulut et al., 2011). Shape recovery characteristic of

41 SMAs upon unloading without any temperature variances are called as superelasticity.

42 Also SMAs having superelasticity are called as superelastic alloys (SEAs). Application of SEAs to civil structures has a potential to contribute both to effective structural control, with shape recovery and structural damping, and to monitoring of structural members with electric resistance feedback.

Several works have been published on the variance of electric resistance with

47 respect to strain under variable temperature and loading conditions in $\mathrm{Ni}-\mathrm{Ti}, \mathrm{Cu}-\mathrm{Zn}-\mathrm{Al}$,

48 Ni-Ti-Cu and Cu-Al-Be SEAs (Ono, 1990; Airoldi et al., 1998; Li et al., 2005; Novak et al., 2008; Gedouin et al., 2010; Cui et al., 2010). It has been reported in the works that linear relationship can be observed between electric resistance and strain in SEAs. The

51 variance of electric resistance is caused by transformation from the austenite to the

52 martensite phases as well as by increase in length, and decrease in cross-section area for 53 a bar in axial tension. However, to the authors' knowledge, Cu-Al-Be SEAs have 
Manuscript submitted for possible publication in Journal of Intelligent Material Systems and Structures Feasibility of Cu-Al-Mn superelastic alloy bar as a self-sensor material by Shrestha et al.

54 inferior superelasticity to Ni-Ti SEAs. Ni-Ti SEAs, on the other hand, come with high

55 material cost and low machinability that largely limit their extensive use in practical 56 applications.

57 The present study examines the feasibility of $\mathrm{Cu}-\mathrm{Al}-\mathrm{Mn}$ SEA bars as sensing devices through electrical resistance feedback. Recently, it was demonstrated that

59 Cu-Al-Mn SEAs have shape recovery capability comparable with Ni-Ti SEAs, while 60 Cu-Al-Mn SEAs have low material cost and high machinability (Sutou et al., 2005;

61 Araki et al., 2011). This paper reports on quasi-static tensile tests performed to study the variation of electric resistance of Cu-Al-Mn SEA bars at room temperature.

63

Test program

65

66 A Cu-Al-Mn SEA bar of 8mm diameter and 150mm length was prepared by Furukawa

67 Techno Material Co., Ltd. The nominal composition of the bar is $\mathrm{Cu}-17$ at.\% Al-11.4

68 at.\% Mn. The SEA bars were obtained by hot forging and cold drawing. The solution

69 treatment was conducted at $900{ }^{\circ} \mathrm{C}$, followed by quenching in water, and they were

70 subsequently aged at $200^{\circ} \mathrm{C}$ to stabilize superelastic property. The martensite start

71 temperature, $M_{\mathrm{s}}$, the martensite finish temperature $M_{\mathrm{f}}$, the austenite start temperature $A_{\mathrm{s}}$,

72 and the austenite finish temperature $A_{\mathrm{f}}$ of above bars are,

$73 M_{\mathrm{s}}=-74^{\circ} \mathrm{C}, M_{\mathrm{f}}=-91^{\circ} \mathrm{C}, A_{\mathrm{s}}=-54^{\circ} \mathrm{C}$, and $A_{\mathrm{f}}=-39^{\circ} \mathrm{C}$. The original $8 \mathrm{~mm}$ diameter 
Manuscript submitted for possible publication in Journal of Intelligent Material Systems and Structures Feasibility of Cu-Al-Mn superelastic alloy bar as a self-sensor material by Shrestha et al.

74 bar was threaded 20mm length at the ends to grip the rod specimen as shown in Figure 1

75 and the remaining central part of the rod of length, $L 106 \mathrm{~mm}$ was reduced with sectional

76 diameter $D$ of $4 \mathrm{~mm}$ in order to avoid fracture at the threaded portion. Here, the relative

77 grain size $d / D$, defined as the ratio between the average grain size $d$ and the bar

78 diameter $D$, is about 4, as illustrated in Figure 2. In Cu-Al-Mn SEA, superelasticity

79 strongly depends on the relative grain size $d / D$, where higher recovery strain can be

80 achieved as the relative grain size increases. Excellent superelasticity can be expected

81 when $d / D=4$ (Sutou et al., 2005; Omori et al., 2013).

82

83

84

85

86

87

88

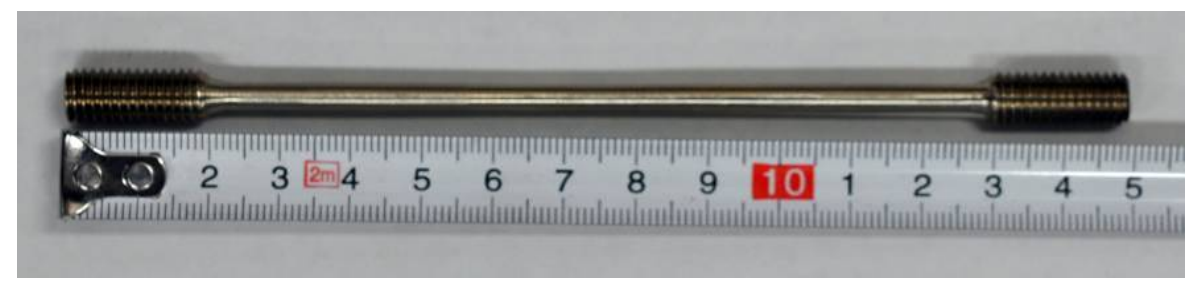

Figure 1. Photograph of an SEA bar test specimen.

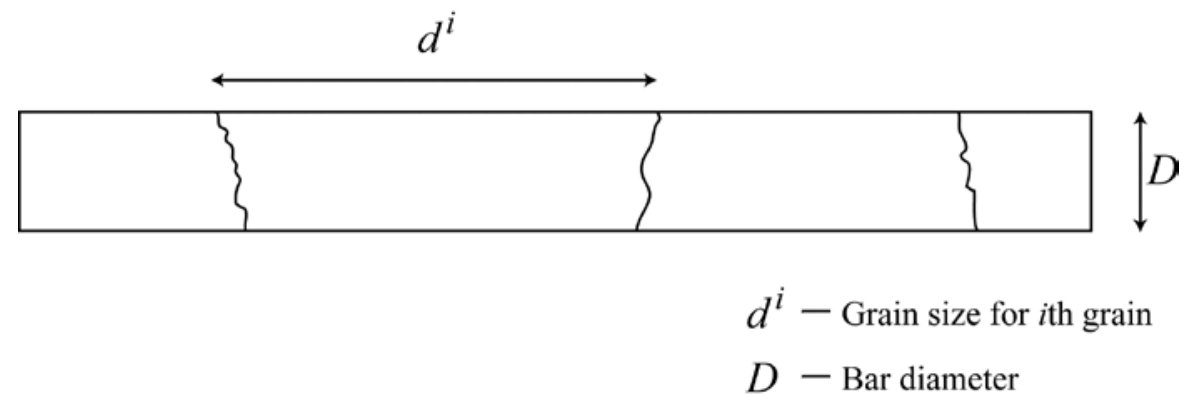

Figure 2. Typical bamboo-like grain structure for Cu-Al-Mn SEA bar with relatively large grain size. 


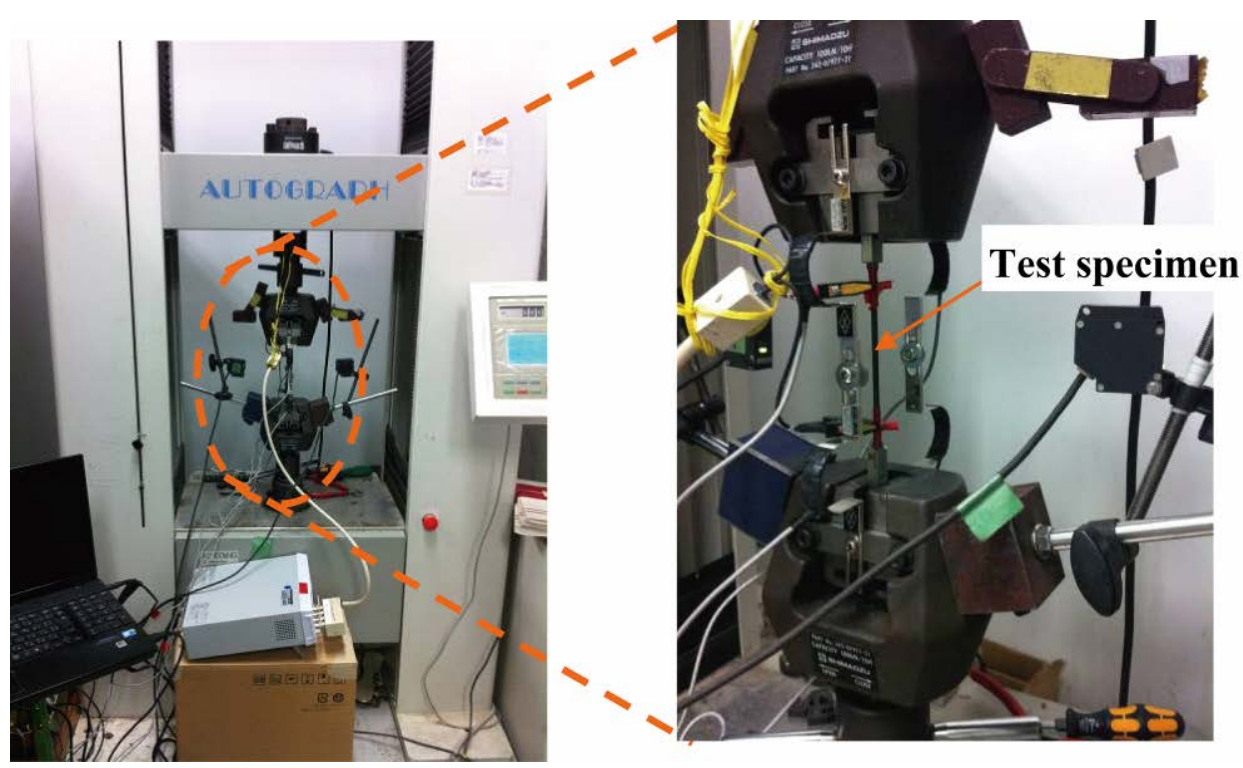

Figure 3. Photograph of test set-up.

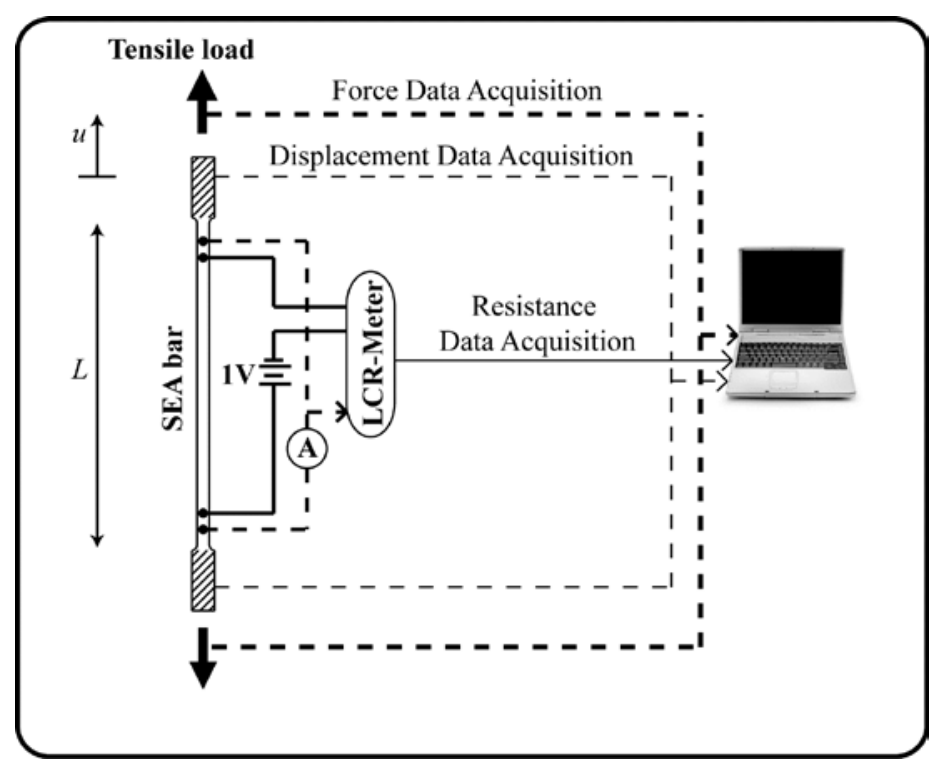

Figure 4. Schematic representation of test set-up and layout. 
Manuscript submitted for possible publication in Journal of Intelligent Material Systems and Structures Feasibility of Cu-Al-Mn superelastic alloy bar as a self-sensor material by Shrestha et al.

Figures 3 and 4 show the test set-up for quasi-static tensile test with specific layout

95 followed to measure the change in electric resistance during the loading/unloading cycle

96 of the SEA bar specimen. Electric resistance measurements were done using

97 LCR-Meter at $1 \mathrm{~V}$ input voltage. Electric resistance measurements were made at the range of $100 \mathrm{~m} \Omega$ for data acquisition. Displacement measurements were made using a set of clip-type displacement transducers (PI-gauges) attached to the cross heads as

100 shown in Figure 3 between the cross-heads. The strain, $\varepsilon=u / L$, was computed taking

101 the change in deformation, $u$, restricted mainly to the reduced sectional length, $L$, as

102 illustrated in Figure 4. Deformation, $u$, was recorded from relative displacement

103 recorded by the PI-gauges. It should be noted here that the strain value obtained by the 104 present technique may be slightly overestimated, which leads to underestimation of

105 Young's modulus. Data sampling was done at $100 \mathrm{~Hz}$ frequency.

106

107

108

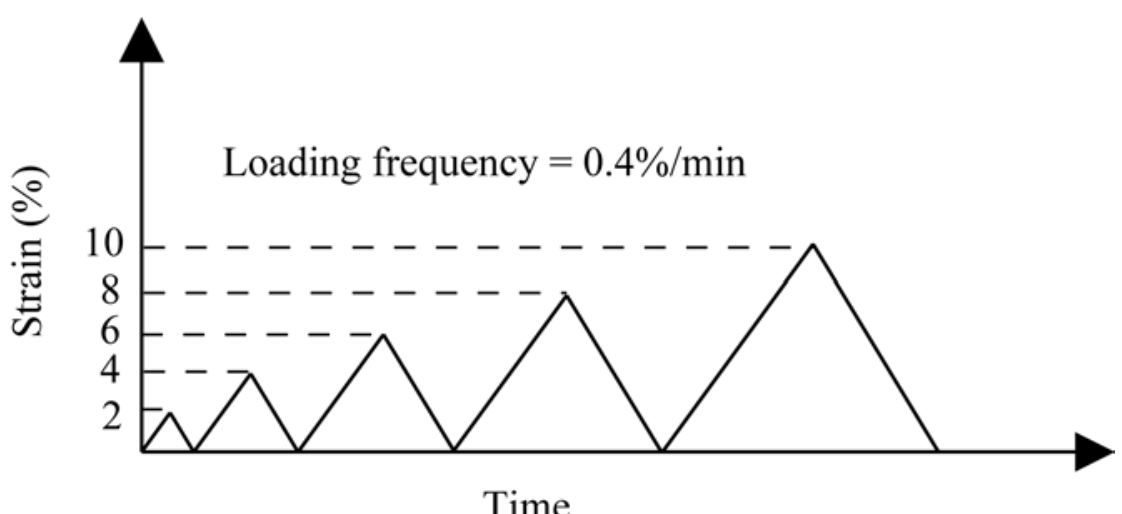

Time

Figure 5. Loading history - Specimen was loaded to a target strain, followed by unloading to zero stress in each cycle. 
Manuscript submitted for possible publication in Journal of Intelligent Material Systems and Structures Feasibility of Cu-Al-Mn superelastic alloy bar as a self-sensor material by Shrestha et al.

110 The adopted loading history is shown in Figure 5. Strain was applied at the strain

111 rate of $0.4 \% / \mathrm{min}$ at room temperature. Five different target strain amplitudes were

112 chosen, 2\%, 4\%, 6\%, 8\% and 10\% consecutively. It should be noted only one SEA bar

113 sample was used in all the tests.

\section{Experimental observations}

117 Figures 6 and 7 illustrates the results for the variation in the electric resistance and in

118 the stress with respect to the applied strain during the quasi-static loading on the given

119 SEA specimen. Observations for the target strain amplitudes of $2 \%, 4 \%$ and $6 \%$ are

120 shown in Figure 6 and for amplitudes of $8 \%$ and $10 \%$ are consecutively shown in Figure

121 7. Electric resistance variation has been presented as the change in electric resistance

122 defined by $\mathrm{d} R=\left(R-R_{\text {initial }}\right) / R_{\text {initial, }}$, where $R_{\text {initial, }}$, where $R_{\text {initial }}$ is the resistance measured

123 at unloaded state. It should be noted that during the tests the value of $R_{\text {initial }}$ recorded

124 was $2.12 \mathrm{~m} \Omega$.

125 Stress versus strain characteristics observed are shown in the left column of Figures

1266 and 7 . For the strain amplitudes of $2 \%$ up to $8 \%$, the characteristic stress-strain 
Manuscript submitted for possible publication in Journal of Intelligent Material Systems and Structures Feasibility of Cu-Al-Mn superelastic alloy bar as a self-sensor material by Shrestha et al.

127 responses observed are similar, shown by typical flag-shaped hysteresis, with

128 transformation stress of $177 \mathrm{MPa}$ and elastic modulus of 30GPa. Here, the

129 transformation stress represents the stress at which the stress-induced transition from the

130 austenite phase to the martensite phase starts to take place, and it was computed as the

$1310.2 \%$ offset stress. The stress plateau is clearly observed with small hysteresis, which is

132 typical for large grain to diameter ratio value $(d / D=4)$. Note here that the relatively low

133 elastic modulus is due to the displacement measurements between grips.

134 Figures in the right column of Figures 6 and 7 illustrate the electric resistance

135 versus strain characteristics for the given strain amplitudes. As shown in the figures,

136 there was slight decrement in resistance measurement before reaching the

137 transformation stress, where the phase transformation initiates. Then afterwards, there

138 was a linear increment of resistance with corresponding increment in strain. Hence, a

139 distinct region is defined for the resistance variation at the start of phase transformation.

140 Furthermore, during the unloading process, the variation in electrical resistance

141 followed almost the same path as during the loading process, with negligible hysteresis

142 observed. 
Manuscript submitted for possible publication in Journal of Intelligent Material Systems and Structures Feasibility of Cu-Al-Mn superelastic alloy bar as a self-sensor material by Shrestha et al.
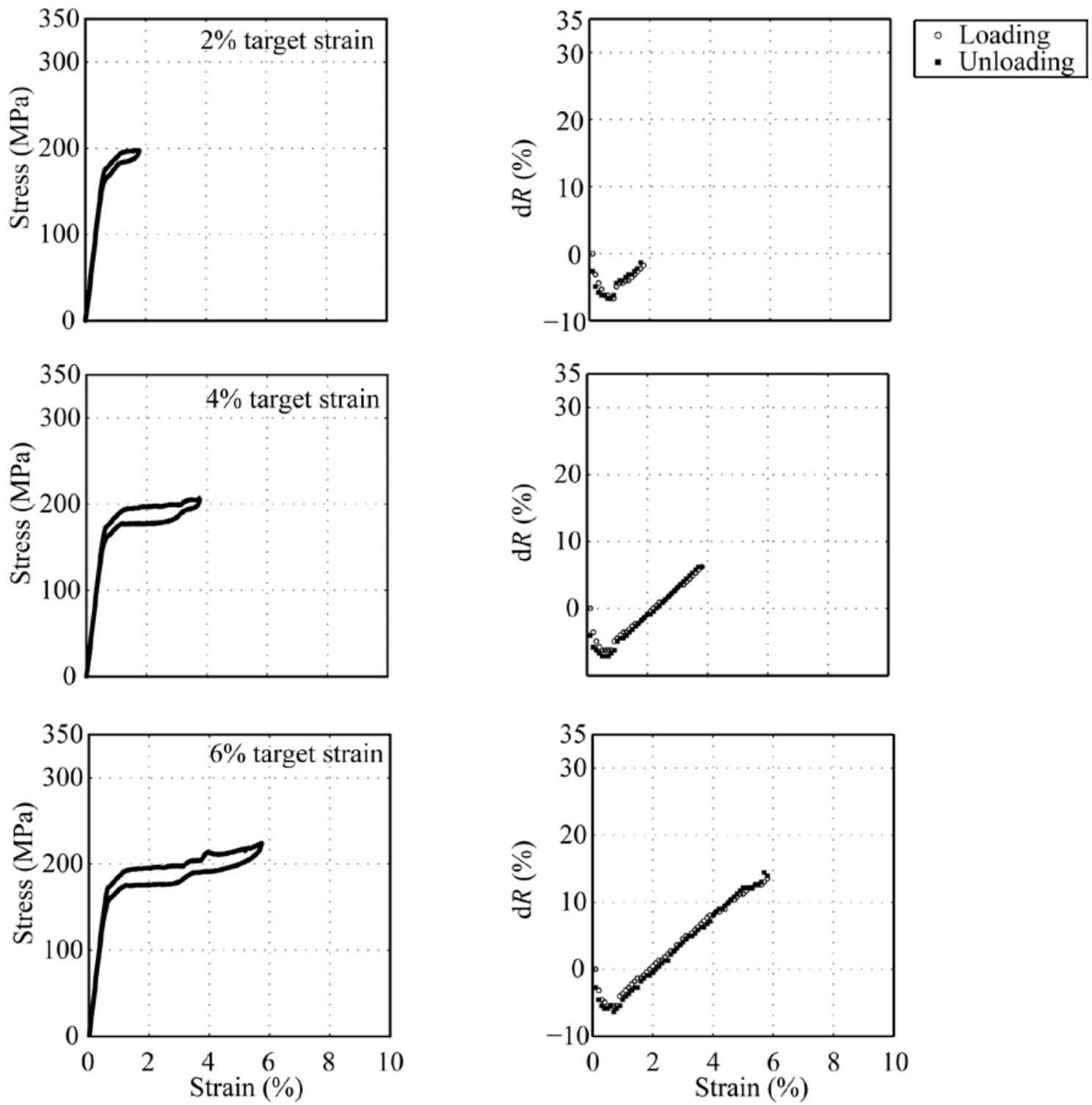

Figure 6. Experimental results for 2\%, 4\% and 6\% target strain:

145 Left - Stress, $\sigma$ versus strain, $\varepsilon$, and Right - Resistance change, $\mathrm{d} R$ versus strain, $\varepsilon$. 

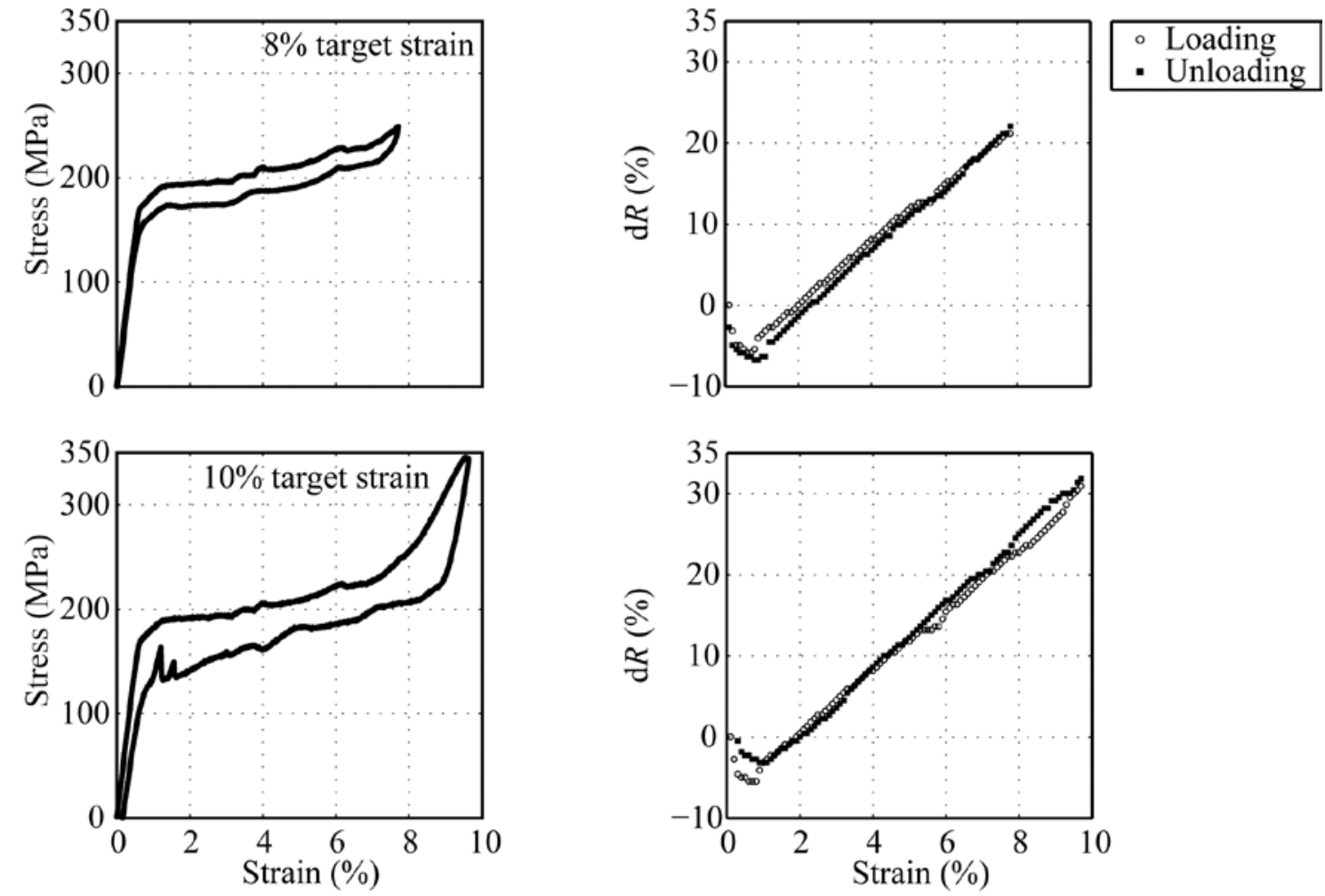

Figure 7. Experimental results for $8 \%$ and $10 \%$ target strain:

148 Left - Stress, $\sigma$ versus strain, $\varepsilon$, and Right - Resistance change, $\mathrm{d} R$ versus strain, $\varepsilon$.

\section{Discussions}

152 Change in electrical resistance for a metal due to applied strain is represented by

$$
\mathrm{d} R=(1+2 v) \varepsilon+\mathrm{d} \rho
$$

154 where $\mathrm{d} R$ is the change in electric resistance defined by $\mathrm{d} R=\left(R-R_{\text {initial }}\right) / R_{\text {initial }}$. Here, 
Manuscript submitted for possible publication in Journal of Intelligent Material Systems and Structures Feasibility of Cu-Al-Mn superelastic alloy bar as a self-sensor material by Shrestha et al.

$155 R_{\text {initial }}$ is the resistance measured at the unloaded state, $\varepsilon$ is the strain, $v$ is Poisson's

156 ratio, and $\mathrm{d} \rho$ is the change in the resistivity of the material under the applied strain

157 given by $\mathrm{d} \rho=\Delta \rho / \rho$, where $\rho$ is the specific resistivity. Further details on equation (1)

158 can be found in Cui et al. (2010).

159 In equation (1), the first term in the right hand side $(1+2 v) \varepsilon$ represents effect of an

160 increase in length, and a decrease in cross-section area for a bar in axial tension. The

161 second term $\mathrm{d} \rho$ represents the physical effect with change in resistivity of the material.

162 Hence, variance in electrical resistance as observed in Figures 6 and 7 is influenced by

163 both the geometrical effect as well as the physical effect. Geometrical effect is straight

164 forward and largely consistent since the value of $v$ usually lies in the range of 0.3 to

1650.45 for most metals. The resistivity term however varies greatly depending on the

166 types of the metals (Kuczynski, 1954; Parker and Krinsky, 1963).

167 During experimental observations, a unique behavior of slight decrement in

168 resistance measurement was observed before reaching the transformation stress as

169 illustrated in Figures 6 and 7. Such observation, however, is not unique and has been

170 documented by Airoldi et al. (1998), and Novak et al. (2008) in the elastic strain range.

171 The initial decrement in the electric resistance is possibly contributed by the change in 
Manuscript submitted for possible publication in Journal of Intelligent Material Systems and Structures Feasibility of Cu-Al-Mn superelastic alloy bar as a self-sensor material by Shrestha et al.

172 resistivity of $\mathrm{Cu}-\mathrm{Al}-\mathrm{Mn}$ SEA bar. It should be noted here that for different metals and

173 alloys, the mechanism of the change in the resistivity may be completely different,

174 depending on its own resistivity characteristic, which requires further scrutiny.

175 For the strain exceeding $8 \%$ as shown in Figure 7 , the slope of the stress-strain

176 curve changes, with possible notification on transformation saturation while no

177 residual strain appeared even when the strain is over $8 \%$. Therefore, it is unclear

178 whether complete phase transformation saturation occurred or not. On the other hand,

179 the slope of electric resistance variation showed negligible difference after $8 \%$ strain

180 value. A detailed study is required to explain more clearly on such distinctive

181 resistance variation observed for $\mathrm{Cu}-\mathrm{Al}-\mathrm{Mn}$ SEA bars under axial tension, both in the

182 elastic range as well as for strain exceeding $8 \%$ value, which is out of the scope of this

183 technical note.

184 The performance of this $\mathrm{Cu}-\mathrm{Al}-\mathrm{Mn}$ SEA bar as a displacement transducer is

185 measured below in terms of some basic performance characteristics, its sensitivity,

186 hysteresis, repeatability and saturation (Murty, 2008). A measure on the sensitivity of

187 sensor material, also defined as its gauge factor, is given by its resistance change per

188 unit applied strain, $\mathrm{d} R / \varepsilon$ in equation (1). An average value of 3.91 sensitivity (gauge 
Manuscript submitted for possible publication in Journal of Intelligent Material Systems and Structures Feasibility of Cu-Al-Mn superelastic alloy bar as a self-sensor material by Shrestha et al.

189 factor) is seen which is relatively high and clearly shows the higher sensitivity

190 characteristic of the particular SEA bar as a displacement sensor. Table 1 summarizes

191 comparison on the sensitivity measured for different classes of SEAs, where all the

192 SEAs show fairly effective sensitivity characteristic. It should be noted that the gauge

193 factor is computed for the region where transformation from austenite to martensite

194 occurs. And, it exhibits a negative gauge factor for small strain region up to $0.8 \%$

195 strain for $\mathrm{Cu}-\mathrm{Al}-\mathrm{Mn} \mathrm{SEAs}$ as reported earlier due to changes in resistivity for the

196 applied elastic strains. Hence, calibration of such SEA bar as sensor would require

197 definition of two distinct regions, before and after the start of transformation.

198 As illustrated in Table 1, the previous works have been mainly done on SEAs of 199 wire samples or thin plates. The present study involves comparatively large 200 cross-sectional diameter $\mathrm{Cu}-\mathrm{Al}-\mathrm{Mn}$ SEA bar, tested at relatively high target strain

201 values as compared to some of the previous works. To better understand the effect of 202 geometrical parameters, tests on different diameters and lengths of SEA samples can 203 be done. Such comparisons need to be done in the future works. 
Manuscript submitted for possible publication in Journal of Intelligent Material Systems and Structures Feasibility of Cu-Al-Mn superelastic alloy bar as a self-sensor material by Shrestha et al.

206 Table 1. Comparison on sensitivity of SEAs (in pseudoelastic regime).

\begin{tabular}{ccccc}
\hline SEA & $\begin{array}{c}\text { Diameter/ } \\
\text { Thickness }(\mathrm{mm})\end{array}$ & $\begin{array}{c}\text { Temperature } \\
\left({ }^{\circ} \mathrm{C}\right)\end{array}$ & $\begin{array}{c}\text { Max. strain } \\
\text { measured }(\%)\end{array}$ & $\begin{array}{c}\text { Sensitivity } \\
(\mathrm{d} R / \varepsilon)\end{array}$ \\
\hline $\begin{array}{c}\text { Ni-Ti wire } \\
\text { (Cui et al. 2010) }\end{array}$ & 0.25 & $70-80$ & 8.0 & $3.50-3.60$ \\
$\begin{array}{c}\text { Ni-Ti-Cu plate } \\
\text { (Airoldi et al. 1998) }\end{array}$ & 0.033 & $70-84.5$ & 2.5 & 8.40 \\
$\begin{array}{c}\text { Cu-Al-Be wire } \\
\text { (Airoldi et al. 1998) }\end{array}$ & 0.80 & 29.3 & 3.0 & 4.80 \\
Cu-Al-Mn bar & 4.00 & 25.0 & 10.0 & 3.91 \\
\hline
\end{tabular}

209 Hysteresis measures the deviation of the sensor's output signal (change in

210 resistance) at the specified point of the input signal (strain) for loading and unloading

211 states. Figure 8 illustrates the results for change in electric resistance for two opposite

212 direction loading at the same strain point. The results are close to the 45 degree dotted

213 line for all the loading cycles. The average value for difference in hysteresis

214 measurement for change in electric resistance, $\mathrm{d} R$ is $0.86 \%$ with standard deviation of

$2150.79 \%$. The results show effectively lower hysteretic influence on the sensor 216 characteristics. 


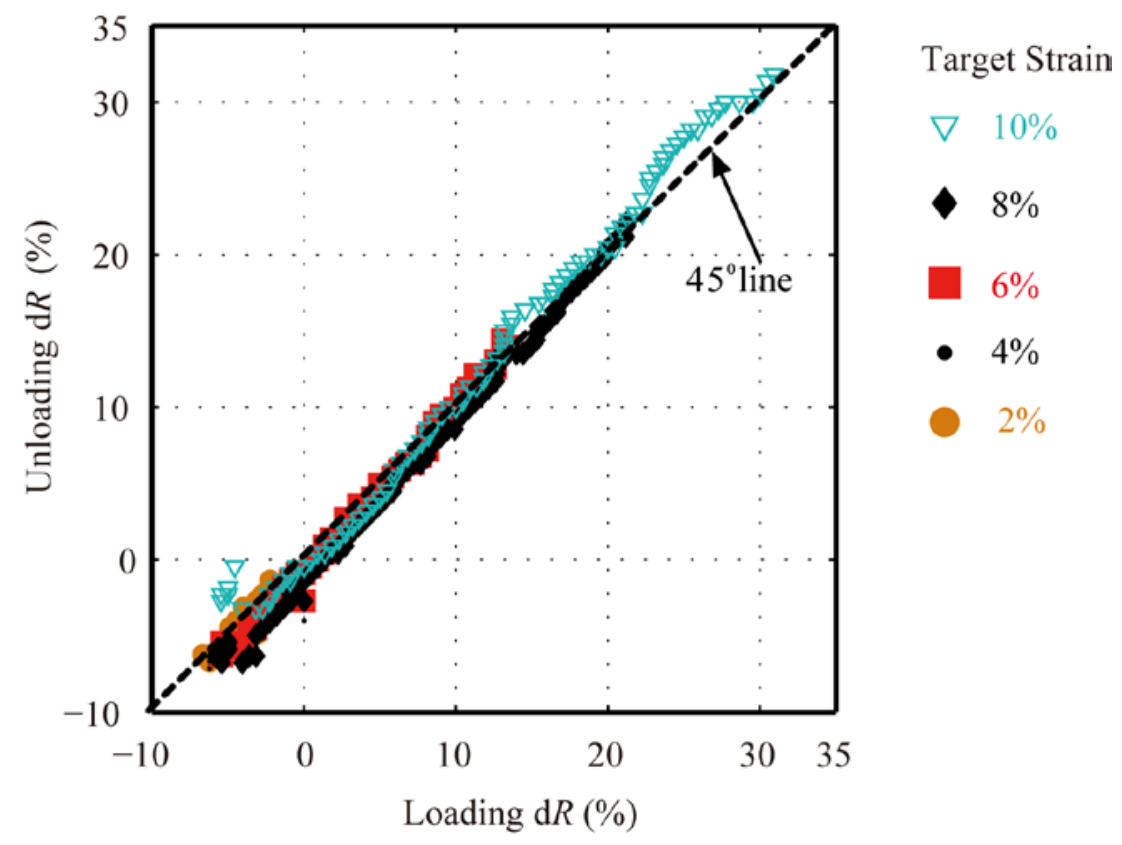

Figure 8. Performance characteristic - Hysteresis and Repeatability.

An effective repeatability characteristic is observed for this particular SEA bar,

with the response for each loading cycle. The output signals of change in electric are relatively close to each other as shown in Figure 8 . An average value for the difference in change in resistance, $\mathrm{d} R$ at the particular strain point when loaded at

225 different strain amplitudes is $0.83 \%$ with standard deviation of $0.64 \%$. The possible

226 effect of cycling on the slope value of resistance-strain curve and also the repeatability 
Manuscript submitted for possible publication in Journal of Intelligent Material Systems and Structures Feasibility of Cu-Al-Mn superelastic alloy bar as a self-sensor material by Shrestha et al.

227

228

229

230

231

232

233

234

235

236 characteristic is an important aspect to better understand the behavior and applicability in practical applications. Wu et al. (1999) reported for NiTi wire, the slope of $\mathrm{d} R$ and strain remain almost same up to 20 cycles of loading, in addition to the residual strain and residual resistance accumulated with each cycle. Further study is necessary on such effect of cyclic behavior on the electric resistance of Cu-Al-Mn SEA bars.

Saturation level for a particular sensor is defined by its operating limit up to which the sensor material exhibits linear behavior and beyond this limit the output signal shows nonlinearity. The test results for the Cu-Al-Mn SEA bars as illustrated in Figures 6 and 7 show perfectly linear behavior for target strain up to 8\%. Negligible nonlinearity with slight hysteresis is seen for strain beyond $8 \%$. This shows relatively large saturation level for these particular Cu-Al-Mn SEA bars as sensor components.

With such linear increment in resistance with strain, high sensitivity, negligible hysteresis, high repeatability, and high saturation limit, the strain measurements from the electric resistance feedback is accurate enough to represent and monitor the actual strain on SEA elements. Such a self-sensor can be easily and conveniently applied to a wide range of smart civil engineering structures with proper electric resistance feedback from the embedded SEA elements, which primarily also work as structural 
Manuscript submitted for possible publication in Journal of Intelligent Material Systems and Structures Feasibility of Cu-Al-Mn superelastic alloy bar as a self-sensor material by Shrestha et al.

control elements.

\section{Conclusions}

248 The variation of electric resistance of $\mathrm{Cu}-\mathrm{Al}-\mathrm{Mn}$ SEA bars has been examined under

249 cyclic tension with five different target strain amplitudes of $2 \%, 4 \%, 6 \%, 8 \%$ and $10 \%$.

250 Slight decrement in resistance was observed before the stress reached the transformation

251 stress. After reaching the transformation stress, linear variation of electric resistance

252 with increasing strain has been clearly observed up to $10 \%$ strain. The linear

253 relationship between the electric resistance and the strain has been also observed during

254 the unloading cycle. Furthermore, performance characteristics in terms of sensitivity,

255 hysteresis, repeatability and saturation were found excellent. The results demonstrate

256 the capability of Cu-Al-Mn SEA bars as a multi-functional component as a structural

257 element as well as a sensing element, which can be used for both structural control and

258 monitoring purposes.

260 Acknowledgements

261

262 The present research was supported by the A-STEP program (\#AS2315014C) provided 
Manuscript submitted for possible publication in Journal of Intelligent Material Systems and Structures Feasibility of Cu-Al-Mn superelastic alloy bar as a self-sensor material by Shrestha et al.

263 by Japan Science and Technology Agency (JST). Prof. Tetsuji Matsuo of Department of

264 Electrical and Electronic Engineering, Kyoto University provided important comments

265 and recommendations during research meetings. All the supports mentioned above are 266 highly acknowledged.

267

\section{References}

269 Airoldi G, Lodi DA and Pozzi M (1998) The electric resistance of shape memory

270 alloys in the pseudoelastic regime. Journal De Physique IV : JP 7(5): C5-507-C5-512.

272

Araki Y, Endo T, Omori T, et al. (2011) Potential of superelastic $\mathrm{Cu}-\mathrm{Al}-\mathrm{Mn}$ alloy bars for seismic applications. Earthquake Engineering and Structural Dynamics 40(1): $107-115$.

Cui D, Song G and Li H (2010) Modeling of the electrical resistance of shape memory wires. Smart Materials and Structures 19(5): 055019.

277 Dolce M, Cardone D and Marnetto R (2000) Implementation and testing of passive control devices based on shape memory alloys. Earthquake Engineering and Strucural Dynamics 29(7): 945-968.

280 Gedouin PA, Chirani SA and Calloch S (2010) Phase proportioning in CuAlBe shape 
Manuscript submitted for possible publication in Journal of Intelligent Material Systems and Structures Feasibility of Cu-Al-Mn superelastic alloy bar as a self-sensor material by Shrestha et al.

memory alloys during thermomechanical loadings using electric resistance variation. International Journal of Plasticity 26(2): 258-272.

Housner GW, Bergman LA, Caughey TK, et al. (1997) Structural control: past, present, and future. Journal of Engineering Mechanics ASCE 123(9): 897-971.

285 Kuczynski GC (1954) Effect of elastic strain on the electrical resistance of metals. Physical Review 94(1): 61-64.

Li H, Mao CX and Ou JP (2005) Strain self-sensing property and strain rate dependent constitutive model of austenitic shape memory alloy: experiment and theory. Journal of Materials in Civil Engineering 17(6): 676-685.

Murty DVS (2008) Transducers and Instrumentation. New Delhi: PHI Learning Private Limited.

292 Novak V, Sittner P, Dayananda GN, et al. (2008) Electric resistance variation of NiTi 293 shape memory alloy wires in thermomechanical tests: Experiments and simulation. 294 Materials Science and Engineering A, 481-482(1-2 C): 127-133.

295 Omori T, Kusama T, Kawata S, Ohnuma I, Sutou Y, Araki Y, Ishida K and Kainuma R 296 (2013) Abnormal grain growth induced by cyclic heat treatment. Science, 
Manuscript submitted for possible publication in Journal of Intelligent Material Systems and Structures Feasibility of Cu-Al-Mn superelastic alloy bar as a self-sensor material by Shrestha et al.

298 Ono N (1990) Pseudoelastic deformation in a polycrystalline Cu-Zn-Al shape memory

299 alloy. Materials Transactions, JIM 31(5): 381-385.

300 Ozbulut OE, Hurlebaus S and Desroches R (2011) Seismic response control using shape

301 memory alloys: a review. Journal of Intelligent Material Systems and Structures 302 22(14): 1531-1549.

303 Parker RL and Krinski A (1963) Electrical resistance-strain characteristics of thin 304 evaporated metal films. Journal of Applied Physics 34(9): 2700-2708.

305

306 Sutou Y, Omori T, Yamauchi K, Ono N, Kainuma R and Ishida K (2005) Effect of 307 grain size and texture on pseudoelasticity in Cu-Al-Mn-based shape memory wire. $308 \quad$ Acta Materialia 53(15): 4121-4133.

309 Wu XD, Wu JS and Wang Z (1999) The variation of electrical resistance of near

310 stoichiometric NiTi during thermo-mechanic properties. Smart Materials and $311 \quad$ Structures 8: 574-578. 